\title{
USING ACTOR NETWORK THEORY TO EXPLORE SUSTAINABILITY ISSUES IN AN ENGINEERING \& SOCIETY COURSE
}

\author{
Robert Irish and Lisa Romkey \\ University of Toronto \\ r.irish@utoronto.ca, lisa.romkey@utoronto.ca
}

\begin{abstract}
This paper explores the use of Actor-Network Theory as a tool for exploring the complexity of sustainability issues in a core Engineering and Society course for second-year students in a large, multidisciplinary engineering program. In the course, Actor Network Theory, which is a method for analyzing sociotechnical issues with an emphasis on the concept of power and its distribution, was introduced to the students through a series of learning activities and an assignment, initially encouraging the students to apply the approach to a system within their own life. Subsequently, the approach was used to analyze complex sociotechnical issues, for example, the use of Coal-based energy in Nova Scotia, and the Coastal Gaslink pipeline dispute in the Wet'suwet'en territory. This paper describes our approach to introducing Actor Network Theory to engineering students, the benefits and limitations of the approach, and the efficacy of the approach for exploring sustainability issues. Other instructors may consider the introduction of Actor Network Theory through courses in Engineering \& Society and Engineering Design.
\end{abstract}

Keywords: Actor Network Theory; Sustainability; Engineering \& Society

\section{INTRODUCTION}

This paper examines the use of Actor-Network Theory as a method for analyzing complex sustainability issues in an Engineering and Society course. Although Actor Network Theory (ANT) is rooted in sociology, the approach has appeal to engineering students through its similarities to systems mapping, but offers an approach firmly rooted in the examination of power - and how power and authority can be transferred and transformed within a system. In this work, we share a summary of ANT, describe our approach to introducing ANT to engineering students, and describe its efficacy and appropriateness as a tool for exploring sustainability issues.

The course described in this paper serves as a required course for all second-year students in a large, multidisciplinary engineering program. The course serves as the students' first experience with social science in their engineering education, but also builds on their first year experience in engineering design through a more in-depth consideration of the impact of technology on society and the environment. Although some students have experience with studies in Philosophy, Sociology and ToK (Theory of Knowledge) based on their high school curriculum, the majority of students do not; questions and considerations of the nature explored in this course are quite new, and more specifically, ANT is built on a nuanced understanding of concepts like agency and power. Therefore, while we invite you to consider the introduction to ANT as a tool, we must also caution that a good understanding of ANT as a method requires significant engagement with the sociology literature. While there are many examples of ANT applied to social systems in the literature, featuring relatively simplistic explanations of the method, we believe it is important to work from first principles and come to understand the underlying structure and motivation of the method.

In previous iterations of the course, we have focused on three traditional theories for sociotechnical systems analysis: Technological Determinism [8]; the Social Construction of Technology [2]; and Technological Momentum [9]. However, all of these approaches work from the same limited assumption regarding the humantechnological relationships: the line of influence is always along a single line from human to technological and back again. In reality, myriad factors influence sociotechnical interactions far beyond whether humans make technology happen or machines shape human behaviour. By moving away from the implied binary, we hoped to enrich students' appreciation of and responsibility for the diverse influences that could (and probably should) be considered in engineering decisions.

\section{ACTOR NETWORK THEORY}

\subsection{The ANT Method}

Actor Network Theory (ANT) originated among sociologists (namely Bruno Latour, Michel Callon, and John Law) in Science and Technology Studies in the 1980's and 1990's $[4,10,11,12]$. Sociology as a discipline of study focuses on significant questions about structure, power and organization in our society. More specifically, 
the Structure/Agency Divide is a defining concept in the discipline. In essence, the Structure/Agency Divide examines whether a set of material or cultural arrangements in our society shape human choice, or whether individuals act independently, drawing from a uniquely human sense of agency, and in turn shape the various arrangements that make up our society. ANT tries to reconcile this question by breaking this divide and acknowledging a more nuanced relationship between material and human, between structure and agency.

The so-called theory is not a theory but a method, enabling the analysis of sociotechnical systems. Through ANT, diverse actors in a system under study are identified; these actors include the environmental ("more-thanhuman"), human, technological artifacts, policy, and the conceptual components of a system. Actors are then mapped to create a network, with relationships identified between the actors; a simple network is represented in Figure 1. The actors in the system, regardless of type, have a set of affordances, which request, demand, allow, and refuse something of the other actors in the system. These affordances define the relationships between the various actors, and theorists suggest that everything of importance in a sociotechnical system is generated from these relationships. These relationships are not static but are subject to re-configuration, resulting in the generation of new "products". ANT acknowledges the various complex bi-directional relationships between technical and nontechnical components in the system, with a particular focus on the generation and transfer of power between different actors.

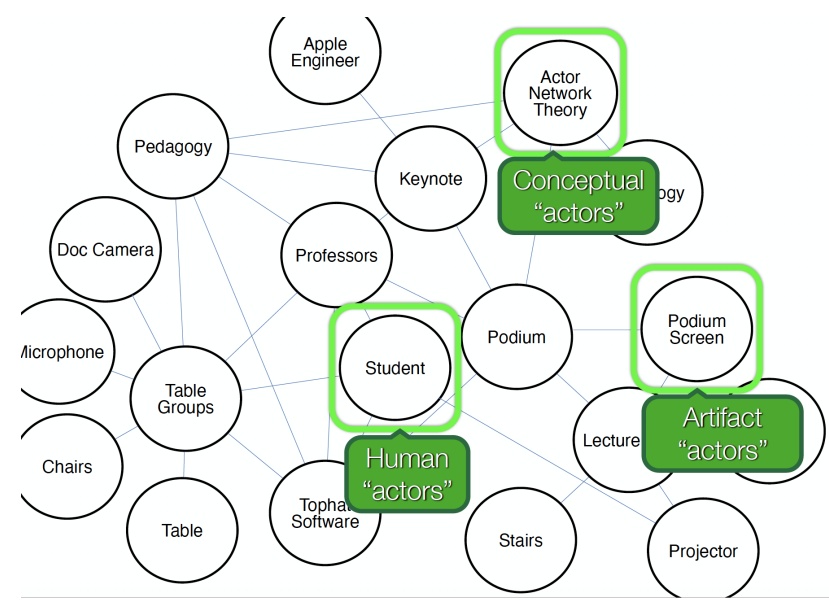

Figure 1: Simple Actor Network Theory Diagram used in the Course as an Example

As noted in the introduction, ANT serves as a method to reconcile the limitations of other theories for sociotechnical systems analysis, all of which assume a single direction between human influence and technological development, or vice versa. ANT addresses another limitation inherent to these other approaches: that the "human" and the "technical" must be divided into two distinct groups. This is not reflective of the actors that comprise a sociotechnical system; many things--an electronic communication, for example--are both "human" and "technological artifact". Engineering artifacts-devices, infrastructure, processes--are created through a series of human decisions and actions. Rather than treating the social and technical as cause and effect, Actor Network Theory tries to treat them as relational instead, negating the need to treat something as "truly technological" or "truly social".

A key tenet of ANT is the concept of generalized symmetry; that is, all actors are positioned in the system and are given even weighting in the analysis; every component and relationship within a system is examined without prejudice in favour of human actors or human enterprise. This is not to say that all actors are afforded equal moral standing, but that all actors are considered in the analysis, requiring a rigorous approach to the identification and mapping of all system components. This rigorous identification supports an examination of all possible relationships within a system, and affords a better understanding of the ways in which the technological and the social influence each other.

Three additional concepts of ANT will help further explain the value of the method to analysis: translation, punctualisation, and patterning. Translation describes the process of connections by which the network comes to be. It requires resistances held by individual actors to be overcome through a process of convergence. Drawing from a sustainability example that will be discussed later in this paper, the process of establishing a new pipeline project can be represented with translation; there are many actors that must come together and "agree", including individuals and groups, environmental and regulatory policy, the technology itself and the more-than-human actors impacted by the project.

Punctualisation is the abstracting of a set of actors into a single actor. Punctualisation can allow significant actors to disappear from view and therefore to escape analysis, but it also allows us to focus analysis at different levels of abstraction within the larger system. When a system is operating as it should, a punctualized network can resemble a black box, until a problem exposes the complexity of the concealed network. For example, if we take a "pipeline" to be an actor in a network, a depunctualisation of this actor would reveal a more complex set of technologies, techniques, and humans involved in laying, maintaining, and repairing pipes in and over land with which the pipeline inevitably interacts. The complexity of a pipeline and its network of actors may be exposed through a burst or leak, but the complexity is always there.

Patterning describes the tendency of one ordered network to impose its pattern on another. So, for example, because an environmental assessment has sufficed for one pipeline, a similar pattern will be imposed onto another 
network, and the same type of assessment will be seen as sufficient by those with power in the network, unless other actors are able to establish resistances that displace the patterns. Patterning can also represent durability over time within a system.

\subsection{Use of ANT}

Although ANT draws from broader questions in sociology, it was developed specifically to examine the sociology of science and technology [4]. The use of ANT has been particularly helpful in analyzing how and why we have the technologies that we do, and evaluating the integration of new technologies into existing human systems. The method is used across several fields, as systems of many types can be mapped to a network. For example, in work by Cresswall, Worth and Sheikh [6], ANT was used to assess the impact of the integration of new information technologies into healthcare settings. ANT provided an understanding of how the integration of new technologies and technology-driven processes may impact distinct individuals and groups in different ways. For example, in their analysis, electronic health record (EHR) served as both an agent of managerial control, perceived to prevent some stakeholders from carrying out some of their critical care-taking duties, while to others, the technology enabled their work and goals. The authors also remarked on the ability to "zoom-in" on the interactions between a particular human and technological actor, while also examining the broader context of the entire system.

In another example, Alcadipani and Hassard argue for the utility of ANT in management and organizational studies [1], and suggest that the approach can be used to examine how some individuals and groups maintain power over others in an organization, the role of managerial networks in the control of resources in an organization, and the use of support structures and services at multiple levels of an organization. Furthermore, the authors argue that the ANT approach acknowledges the ever-evolving nature of organizational development - that organizations only exist because they are continuously "organizing", and that the politics of an organization are never within a single system or relationship, but are embodied in different sets of relations, happening and evolving in parallel.

We offer these as two examples of the use of ANT in the analysis of socio-technical systems. Many other examples can be found in other contexts, including healthcare studies [7] and human-environmental systems [14].

\section{INTRODUCING ANT TO ENGINEERING STUDENTS}

In a second-year course on Engineering and Society, we introduced Actor Network Theory through a set of instructional videos, a reading by John Law [12], and a review of a case study of the Delhi Water System [14]. In the instructional videos, students were introduced to ANT through a series of familiar examples to help introduce the concepts, some of which are quite abstract. For example, we used the classroom as a system to model, and demonstrated the shift in actors and relationships between actors upon shifting to online learning. Using familiar examples allowed us to draw attention to the way they use technology to mediate communication, and the role that family heirlooms play in connecting family members over space and time.

The Delhi water system case study served two main purposes: first, it illustrated the value of ANT in professional analysis by a field closely related to engineering. Thus, students were introduced to its efficacy. Second, it offered a tangible example for defining particular types of actors in a network that was relatively complex. These two goals worked well to set up future, more open-ended case studies in our classroom discussion and in assignments.

After offering both synchronous and asynchronous learning modules introducing ANT, students had an opportunity to participate in a discussion seminar, in which they were tasked with using ANT to map and analyze their undergraduate engineering program. This approach provided students with an opportunity to build explicitly on the lecture material and develop an understanding through a familiar context.

\subsection{ANT Assignment}

To help students understand the potentialities and challenges of ANT, we created an assignment for students to represent aspects of their own lives in an actor network. We broke the assignment into two tasks:

1. Create a visual representation of an aspect of their lives within an actor network;

2. Write a short analysis of aspects of that actor network to explore the power relations in their own lives.

By grounding their exploration in the familiar territory of their own lives, they could focus on the methodology itself and what it reveals. Most significantly, it revealed the dependencies and interdependencies on artifact actors, such as their devices (phones, laptops) and conceptual systems (e.g. the university, family). The simplicity of this assignment structure allowed students to develop the complexity in their own actor network and analyze it in a relatively low-risk environment.

\section{ANT AND THE ANALYSIS OF SUSTAINABILITY ISSUES}

After introducing the concept to the students, we continued to use Actor Network Theory in the course, particularly to analyze sustainability issues, such as the use of Coal-based energy in Nova Scotia, and the Coastal 
Gaslink pipeline dispute in the Wet'suwet'en territory. Both of these examples benefitted from having a broad network of actors--human and more-than-human, technical and conceptual--to establish the nuances of critical decisions being made with significant implications for sustainability in Canada.

In these complex sustainability issues, the application of generalized symmetry encourages an examination of the relevance of technology to both the promotion and prevention of sustainability, and the relationship between human actors and policy, for example, in the development and implementation of these technologies. The emphasis on relationships in particular allows students to understand what is generated--or lost--as the result of the relationship between actors and their affordances. For example, as we consider contentious pipeline projects utilizing ANT analysis, students must consider a more complete list of stakeholders and the processes and tools used to mediate discussion and negotiation, and the relationships between the various stakeholders and tools used. The complexity of the project is exposed, and students are encouraged to consider the power structures and imbalances that exist.

In the course more broadly, students are introduced to various ethical thinking frameworks, including an indigenous ethic of care framework [17]. This, in turn, influences the language we used in the application of ANT. Although ANT, as noted, acknowledges actors of all types in a system, the term "more-than-human actor" is not typically used as terminology to identify environmental actors, such as wildlife, plantae and energy flows in a system, for example. Drawing from Zoe Todd's work on indigenous ways of knowing [15, 16], we introduced students to a worldview in which rivers and fish and even ancient decayed beings who have become oil in oil sands are considered "kin" and are upheld in kinship relations. ANT supports this type of application as a depunctualisation of "resources" or "water" to allow for examinations of the relations and resistances in the system as we understand it.

Although ANT is not a method of ethical analysis, it does create an in-road to address some of the key questions in environmental ethics. For example, a dilemma faced in environmental ethics is how moral standing should be applied to more-than-human actors, who lack the same level of reciprocity and free will as human actors, and are therefore not typically afforded the same level of moral standing. Reflecting, for example, on sustainability frameworks like the Brundtland Report [3], the focus is on meeting the needs--of both human actors now, and in the future--rather than more-than-human actors. This instrumental approach to environmental ethics is common. We value the environment as an entity to further some other ends--our own--rather than intrinsically, as an entity deserving of its own moral standing. Through the use of generalized symmetry, the actors in a network are all considered, and although the intention is not to apply an ethical analysis, ANT invites us to consider relationships beyond the ones that explain how humans can best capitalize on more-than-human actors. We are forced to consider the relationships between more-than-human actors in a system through a more intrinsic framing. Once again, we reflect on an Indigenous Ethic of Care approach, which emphasizes the environment as a set of interdependent relationships that motivate reciprocal responsibilities [17]; ANT can draw attention to these relationships.

\subsection{Coastal GasLink Case Study}

By using this framing in our discussion of the sociotechnical issues surrounding the Coastal Gaslink pipeline, we were able to incorporate multiple competing worldviews by representing not only the conventional interests but also the interests of Wet'suwet'en hereditary chiefs, and the interests of the land, plants, and animals. In doing so, the power relations--including the lack of power of certain actors--became clear almost immediately to reveal the pressures and problems in any bilateral negotiation between corporate, government, and indigenous groups. Not to mention the unspoken-for morethan-human actors.

In working through the case, we provided detailed background on numerous stakeholders--the company, elected and the hereditary Wet'suwet'en chiefs, the mayor of Kitimat, B.C. (the municipality that will most benefit from the development), provincial government, and bureaucratic structures. We also looked at the conflict within Wet'suwet'en society with its elected and hereditary chief structures (the former a fixture of colonialism, the latter traditional self-government). As part of the process, we had students work in groups to brainstorm their own networks for the case and used the activity to encourage them to move past a simplistic understanding of actors.

We set up several small, partial actor networks to demonstrate the specifics of the relations between individual groups, and the translations that structured them as a network--including the resistances and mediators that influence the structure of the network. These mininetworks provided scaffolding to understand particular kinds of relations and the patterning that shaped them. Then, we assembled the various networks together into a larger network. So we could note how patterning from other large projects translated the network relations to function in particular ways and how the patterning disempowered various actors through punctualisations (e.g. "consultations with indigenous populations"). For example, the British Columbia Environmental Assessment Office has established processes for environmental consultations that include specific kinds of communication and specific scientific testing, but which do not include kinship relationships with flora and fauna. By not privileging scientific testing and standard consultation, 
ANT opens the possibility of considering other relations between actors in the network.

Since students had been prepared with a range of ethical frameworks and Indigenous approaches to knowing, we could use the sites of resistance revealed by depunctualising actors in the network to explore possible range of ethical responses to the case as well.

\subsection{Nova Scotia Coal Case Study}

As another example, we introduced Nova Scotia Coal as an actor network with sustainability implications. Coal is responsible for $63 \%$ of Greenhouse gases (GHGs) from electricity generation in Canada. Nova Scotia produces $56 \%$ of its electricity from coal. Despite that, Nova Scotia was given an exemption from Canada's national timeline to phase out coal-powered electricity generation after arguing that the timeline was too short for the lifespan of the generating stations. Ironically, such stations are usually considered serviceable for 40 years, and the main plants in Nova Scotia have already passed that milestone. Nova Scotia argued that if it were forced to eliminate coal too soon, it would be forced to use Natural Gas, and would thus be locked into another GHG-producing generation system. In addition, we looked at the competing commitments of different levels of government: the federal government has committed to ending coal power; Nova Scotia resists. As we sketched out a wider actor network, we included alternative power generation including tidal and wind power. Both approaches are successful in Nova Scotia. However, as soon as we introduced tidal power, we raised the challenge of competing demands for ocean, namely the fisheries (lobster, scallops, etc.) which have significant power due to the large financial stake in the province.

With this case study, we kept our discussion quite brief and open-ended. We then introduced the case again on the midterm, with an ANT diagram. There we were able to ask students to evaluate the nature of specific relations and establish the power between different actors within the network. Interestingly, the specifics of the case pit one more-than-human actor--the lobster--against another--the air. By having the students analyze a network that had been discussed already, we were able to see how students synthesized and extended their understanding through the midterm questions.

In addition, the midterm prompted the students to use the Actor Network as a foundation for ethical reasoning using a principled approach. While ANT is insistently not an ethical framework in itself, as noted, ANT allows or even insists on the consideration of all actors (or as many as possible), which is a virtue for ethical reasoning. By shifting from the broad set of actors to ethical reasoning, the students were primed to evaluate the ethical cost/benefit on more than simply human expediency.

\section{BENEFITS AND LIMITATIONS}

In our experience, ANT proved to be a useful approach for the analysis of sociotechnical systems. In this section, we will explore the benefits and some challenges in using ANT to facilitate learning with engineering students.

\subsection{Benefits of ANT to Engineering Students}

By scaffolding our discussion of ANT from the familiar to the more challenging and helping students understand both the process of building a network and its analytical implications, we think we have started students on a mental practice that will allow them to consider a broad range of sociotechnical factors in their thinking and decision making. Indeed, on later assignments and the final exam, students made use of ANT even when it was not required by the assignment in order to explicate specific points they wanted to make. Admittedly, we are still working within the same course, but this at least suggests that students found the method useful and usable.

ANT offers a number of meaningful benefits to students learning about the interplay between society, engineering, and ethics. By providing a method, ANT helps students think clearly in abstract and open-ended situations. By refusing to privilege human over technical or more-thanhuman actors, ANT pushes students to see relations differently and consider actors that may not be obvious at the outset. And, by offering an organic approach that builds from simple relations to complex networks, it works inductively--like an engineering research process--to stretch students' outlooks beyond the familiar, even to incorporate worldviews that are disparate from their own.

In this way, they can "model" a sociotechnical system with sensitivity and richness. Since modelling and the visual representations that entails are natural for engineering students, the method resonates with our students in ways that the more traditional approaches to analysis never have. Moreover, although ANT is not explicitly a method for ethics, it does expose power relations in novel ways that provide the possibility for deeper principled ethical reasoning once the network and the relations are better understood.

\subsection{Challenges in teaching ANT}

For anyone wanting to employ ANT in their own Science and Technology context--or other related context-there are some challenges. We identify three. Probably foremost is the challenge of understanding the method well enough to engage in it meaningfully with students. Neither of us is a sociologist, and none of the work by the originators is easy reading; however, we found wrestling with the method itself to support our thinking about engineering and society in ways that allowed us to frame problems differently and develop new understanding of sociotechnical systems. We found the method especially helpful to allow us to acknowledge indigenous ways of 
knowing as related to the environment. We expect others would find similar benefit.

Second, anyone wanting to use ANT should be aware of the various criticisms that have been levelled by its detractors. They can be summarized along four main lines [13]:

1. the inclusion and exclusion of actors can be arbitrary or biased to particular ends;

2. humans and non-humans are treated equally in the network in a way that decentres the social, leading to political impotence;

3. non-human actors are privileged with status that is higher than human actors and out of keeping with the entities themselves; and

4. it fails to account for agency and structure--both of which are dismissed as simple effects of networks by ANT theorists, so to speak of structures is really to speak at cross purposes with ANT.

Close readers will see the logical inconsistency in the critiques above: if inclusion or exclusion can result in bias, and if elevating non-human actors can privilege them, then politics are indeed in play. Indeed, from our standpoint, the equal treatment of all actors is precisely the virtue of ANT because it invites our students to consider actors that may otherwise be too easily ignored. Moreover, the complaint that ANT does not account for structure is actually a misreading of actor network accounts. What ANT refuses to do is presuppose structures; after all, structures emerge as a result of translations and ordering of actors in a network. That such entities appear as structures does not mean they are organizations ex nihilo; on the contrary, they are organizations precisely because they are patterned actor networks that have reached a stable (punctualised) state.

The complaint that ANT is politically impotent is just misguided. It is politically agnostic; however, given that the method is concerned with relations of power, it is anything but impotent. As our examination of the Wet'suwet'en case study showed, by raising the challenges in the case, an ANT account can help explain to nonindigenous peoples why the more-than-human actors can and should have standing equal to the multi-billion-dollar natural gas industry. Simply by making the dynamics visible and by refusing to accede to the ideology of the corporation, ANT raises the possibility of other arrangements--other translations--some of which could be more stable, more fruitful, and more sustainable than those we are inclined to see initially.

Finally in teaching ANT, we had to surmount challenges in vocabulary. The vocabulary comes from Sociology and has to be learned and employed by engineering students. The vocabulary becomes especially difficult given that many of the terms have everyday meanings (e.g. translate) that offer little help in the precise use of ANT accounts. Students often have trouble seeing past the everyday meanings. This stumbling block may cause particular difficulty for students working in their second language as they may lack the linguistic flexibility in English to employ the words in the specific technical denotative meaning.

\section{Conclusions ANd Future Work}

Although we faced challenges in the use of the method, given its complexities and roots in a relatively unfamiliar discipline (to both us and the students), we ultimately found great utility in Actor Network Theory. Likewise, many of our students started using ANT as an analysis tool to help structure their thinking and analysis of complex sociotechnical issues. The fact that the method involves visual representations and is consistent with systems thinking in engineering makes ANT seem to resonate with them.

We will certainly continue to explore the affordances of Actor Network Theory for empowering students to analyze sociotechnical systems, to provide a basis for understanding worldviews outside their own and as a foundation for ethical reasoning, this last despite the originators' claim of its moral neutrality.

\section{Acknowledgements}

We would like to acknowledge our students, and in particular note their efforts through a challenging term of remote teaching and learning. We would also like to acknowledge our teaching team who led the discussion seminars, and so took the learning journey with us.

\section{References}

[1] R. Alcadipani and J. Hassard, "Actor-Network Theory, organizations and critique: towards a politics of organizing", Organization, Vol. 17(4) 419-435, 2010.

[2] W. Bijker, T. P. Hughes, and T. J. Pinch, eds., The Social Construction of Technological Systems. Cambridge, Mass., MIT Press, 1987.

[3] Gro Haarlem Brundtland and World Commission on Environment and Development, Our Common Future. Oxford: Oxford University Press. 1987.

[4] Michel Callon, "Some elements of a sociology of translation: domestication of the scallops and the fishermen of St Brieuc Bay," in J. Law, ed., Power, Action and Belief: a new sociology of knowledge? London, Routledge, pp.196-223, 1986.

[5] Darryl Cressman, "A Brief Overview of ActorNetwork Theory: Punctualization, Hetero- geneous Engineering \& Translation" Centre for Policy Research on Science \& Technology, 2009. $<$ https://summit.sfu.ca/item/13593>

[6] K.M. Cresswell, A. Worth, \& A. Sheikh, "ActorNetwork Theory and its role in understanding the implementation of information technology 
developments in healthcare", BMC Med Inform Decis Mak, Vol. 10(67), 2010.

[7] Amit Desai et al., "Taking data seriously: the value of actor-network theory in rethinking patient experience data," Journal of Health Services Research \& Policy, Vol. 22(2) 134-136, 2017.

[8] Robert Heilbroner, "Do machines make history?" Technology and Culture 8, no. 3 pp. 335-345, 1967.

[9] Thomas Hughes, "Technological momentum," in Leo Marx and Merritt Roe Smith, eds., Does Technology Drive History? The Dilemma of Technological Determinism. Cambridge, Mass.: MIT Press, pp. 101113, 1994.

[10] Bruno Latour, Reassembling the Social. Oxford: UP, 2005, 301 pp. \{ISBN: 978-0-19-925604-4\}

[11] Bruno Latour, "Where are the missing masses?" Wiebe E. Bijker and John Law, eds., Shaping Technology/Building Society: Studies in Sociotechnical Change. Cambridge, Mass.: MIT Press, pp. 225-258, 1992.

[12] John Law, "Notes on the theory of the actor network: ordering, strategy and heterogeneity." Systems Practice, vol. 5, pp.379-393, 1992.

[13] Chris McLean and John Hassard, "Symmetrical absence/symmetrical absurdity: critical notes on the production of actor-network accounts," Journal of Management Studies 41:3 May pp.493-519, 2004.

[14] Deya Roy, "Understanding the Delhi urban waterscape through the actor network theory" Public Works Management \& Policy, Vol. 20(4), pp.322-336, 2015.

[15] Zoe Todd, "Refracting the state through human-fish relations: fishing, indigenous legal orders and colonialism in north/western Canada," Decolonization: Indigeneity, Education \& Society Vol 7., No 1, pp. 6075, 2018.

[16] Zoe Todd, "Fish, kin and hope: tending to water violations in amiskwaciwâskahikan and Treaty Six territory," Afterall, Vol.43, pp.103-107, 2017.

[17] Kyle Powys Whyte and Chris J. Cuomo, "Ethics of caring in environmental ethics: indigenous and feminist philosophies" in The Oxford Handbook of Environmental Ethics. Eds. Stephen Gardiner and Allen Thompson. pp.234-247, 2016. 